\title{
Optimization of Biofertilizer Production and its Application in Plants using Pot Culture Technique
}

\author{
Sandip Bandopadhyay \\ Department of Microbiology, Bidhannagar College, Government of West Bengal, EB - 2, Sector - 1, Salt Lake, \\ Kolkata - 700 064, West Bengal, India.
}

\begin{abstract}
Mass production of Bacillus thuringiensis A5-BRSC culture as biofertilizer, using cheap carbon sources revealed that mashed potato is the most effective carbon source followed by arrowroot and liquid waste of boiled rice. Biomass was mixed with charcoal, the carrier, and applied to the pots to study its plant growth stimulating effect using Abelmoschus esculentus as test plant. Biofertilizer inoculated plants showed high shoot and root length, high numbers of leaves, more numbers of fruits, increased fruit weight in comparison to control plants where no biofertilizer was inoculated. Microbial activity of biofertilizer in pot soil was studied by both soil dehydrogenase assay and carbon evolution method. Both of the study revealed that the biofertilizer is stable in soil condition up to $\mathbf{4 5}$ days.

Keywords: Biofertilizer, Bioprocess productivity, pot culture, charcoal, Bacillus thuringiensis.
\end{abstract}

*Correspondence: microbiosandip@gmail.com; 9831896029

(Received: 08 July 2019; accepted: 14 December 2019)

Citation: Sandip Bandopadhyay, Optimization of Biofertilizer Production and its Application in Plants using Pot Culture Technique, J Pure App/ Microbiol., 2019; 13(4):2159-2167. https://doi.org/10.22207/JPAM.13.4.28

(C) The Author(s) 2019. Open Access. This article is distributed under the terms of the Creative Commons Attribution 4.0 International License which permits unrestricted use, sharing, distribution, and reproduction in any medium, provided you give appropriate credit to the original author(s) and the source, provide a link to the Creative Commons license, and indicate if changes were made. 


\section{INTRODUCTION}

Biofertilizers are active microbial inoculants that are applied to the seeds or the plant roots directly. These active microflora colonize on the rhizosphere and stimulate the growth of host plant by supplying essential primary nutrients or phytohormones. Though the use of biofertilizer was started in the $19^{\text {th }}$ century, sustainable agriculture of $21^{\text {st }}$ century also needs such pollution-free fertilizers to fulfil the tremendous need of food grains and vegetables.

Reports of biofertilizer research in India revealed that the use of Rhizobium strains increase crop yield in pulses, groundnut, soybean etc. Use of Azotobacter and/or Azospirillum results in better yield of maize, barley, oat, sorghum, sugarcane, rice etc. Combined use of biofertilizer Bacillus megaterium var. phosphaticum, a Phosphate Solubilizing Bacterium (PSB) with chemical phosphate fertilizer reduced the number of PSB in soil and plant required $25 \%$ more phosphate for growth, but single inoculation of that organism enhanced PSB population in rhizosphere, availability of phosphate in soil, increased growth rate and yield of sugarcane ${ }^{1}$. Potential use of biofertilizer for sustainable agriculture in eco-friendly manner was reported by various groups of scientists in last two decades ${ }^{2,3}$. Mass cultivation of such potent strains was also attempted in several cost effective ways. Plant Growth Promoting Rhizobacterium (PGPR) strain Azotobacter chroococcum was cultivated by single batch, repeated batch and fed batch process in stirred tank bioreactor in a very cost effective way4. Both chemically defined media as well as complex media was used with a carbon source and essential inorganic salts. Glucose and sugar beet molasses was used as carbon sources for those medium respectively. The reports revealed that the use of glucose in chemically defined media yielded the highest biomass production, where as, in case of complex media same was happened in molasses, although in both cases a large amount sugar was unconsumed. Highest biomass yield was obtained in fed batch fermentation using complex medium.

Biofertilizer production in commercial scale requires suitable PGPR strains and their proper preservation, a stable and chemically inert carrier like peat, lignite or charcoal, proper packaging and marketing of the final product ${ }^{5}$.
However, fly-ash generated from thermal power plants might be successfully used as carrier for biofertilizers, although it had minute toxic effects due to presence of negligible amount of heavy metals $^{6}$.

In India, southern states (except Andhra Pradesh), western states, Madhya Pradesh and Rajasthan have a steady increase in biofertilizer demand ${ }^{7}$. The report of State Department of Agriculture also revealed that West Bengal was the highest biofertilizer producing state in Eastern India and has a great marketing possibility of biofertilizers from commercial point of view. The main constrain of biofertilizer production is lack of stable PGPR strains. Most of the strains exhibit good results in laboratory conditions but becomes misfit in the fluctuating environmental conditions of agricultural fields. Moreover, some strains get mutated either during fermentative mass production or in field condition. Contamination during fermentative production, storage or packaging is another major problem regarding biofertilizer research ${ }^{8}$. Shelf life of biofertilizer greatly depends on suitable carrier materials for microorganisms. Unavailability of suitable carriers or their short shelf life sometimes became a major problem in biofertilizer research. Though biofertilizer research has golden future from both agricultural as well as economic aspect, lack of proper marketing strategy and awareness of the farmers makes the progress of biofertilizer research slower in comparison to western countries.

It has been reported that chemical fertilizers affect the balance of bio-geo chemical cycle of the environment. They may pollute ground water or may increase the hazard of chemical spills or even may increase green house gases in the environment ${ }^{9,10}$, where as biofertilizers using high yielding strains of PGPR, the probability of environmental pollution is $\mathrm{ni}^{111,12}$. It was reported that NFB like Rhizobium could fix $50-300 \mathrm{~kg}$ of Nitrogen/ha (N/ha) and Azotobacter and Azospirillum could fix $15-20 \mathrm{~kg} \mathrm{~N} / \mathrm{ha}$, where as the use of PSB as biofertilizer increased the yield of crops $200-500 \mathrm{~kg} / \mathrm{ha}$, and therefore $30-50$ $\mathrm{kg}$ of chemical fertilizer like super phosphate could be saved ${ }^{13}$. The energy sources required for the synthesis of chemical fertilizer are natural gas, petroleum and coal. All these energies are non- 
renewable and costly, but in case of biofertilizer, energy requirement is fulfilled by costless renewable energy sources like plant synthesized carbohydrates ${ }^{7,8,14}$. Therefore, from the view point of energy requirement, biofertilizer is more reliable than chemical fertilizer. Moreover, increasing demographic pressure and food demand requires the utilization of biofertilizer for crop production. Application of potent PGPR as biofertilizer may give better crop yield, which can fulfil the global problem of nutrition.

The aim of the present study is the mass production of biofertilizer using the isolated strain Bacillus thuringiensis A5-BRSC and to apply the biofertilizer in the pot culture to examine its plant growth promoting effects. The future target is to apply the biofertilizer in the agricultural fields.

\section{MATERIALS AND METHODS Inoculum}

Bacillus thuringiensis A5-BRSC, isolated from the agricultural soil of West Bengal, India was used as biofertilizer strain in the present study ${ }^{15}$.

\section{Selection of Carrier}

Charcoal was used as carrier for biofertilizer production. The carrier was mixed at 1:1 ratio $(\mathrm{w} / \mathrm{v})$ with the centrifuged culture of $B$. thuringiensis A5-BRSC. Centrifuged culture from 1 I nutrient broth medium (initial cell density: $10^{6}$ $\mathrm{CFU} / \mathrm{ml}$ ) was mixed with $50 \mathrm{ml}$ of $0.2 \mathrm{M}$ phosphate buffer solution ( $\mathrm{pH}: 7.2)$. The culture slurry was mixed with $50 \mathrm{~g}$ of carrier particles.

\section{Determination of physicochemical properties of carrier}

Some physicochemical properties like $\mathrm{pH}$, moisture content, water retaining capacity, bulk density and organic carbon (\%) of charcoal was determined. $\mathrm{pH}$ of the carrier was measured directly by mixing the carrier particles in distilled water and filtered through Whatman filter paper. $\mathrm{pH}$ of the filtrate was estimated by using $\mathrm{pH}$ meter. Organic carbon was estimated by slightly modified method of Walkley and Black (1934) ${ }^{16}$. $2 \mathrm{~g}$ of carrier particles was mixed with potassium dichromate $\left(\mathrm{K}_{2} \mathrm{Cr}_{2} \mathrm{O}_{7}\right)$ and concentrated $\mathrm{H}_{2} \mathrm{SO}_{4}$. The solution was swirled and allowed to cool. Then $0.1 \mathrm{ml}$ aliquot from the digested sample was mixed with 85\% phosphoric acid to eliminate interference of $\mathrm{Fe}^{3+}$ ions. Excess $\mathrm{K}_{2} \mathrm{Cr}_{2} \mathrm{O}_{7}$ present in the solution was titrated against $0.5 \mathrm{~N}$ ferrous ammonium sulphate
$\left[\mathrm{Fe}\left(\mathrm{NH}_{4}\right)_{2}\left(\mathrm{SO}_{4}\right)_{2}, 6 \mathrm{H}_{2} \mathrm{O}\right]$, using diphenylamine as indicator. To determine moisture content $5 \mathrm{~g}$ of carrier was taken on a dry Petri dish. It was heated in hot air oven for 2 hours at $65^{\circ} \mathrm{C}$ and constantly weighed. The sample was then cooled in desicator and weighed again. Percentage loss of weight was calculated to determine moisture content. Bulk density was estimated by weighing dry empty $100 \mathrm{ml}$ cylinder (W1 g) as well as cylinder along with $100 \mathrm{ml}$ of sample (W2 g). Volume of 100 $\mathrm{ml}$ of sample in the cylinder was noted as $\mathrm{V} 1 \mathrm{ml}$; volume of $100 \mathrm{ml}$ water was taken as V2 $\mathrm{ml}$ and bulk density was calculated by following formula: Bulk density $=(\mathrm{W} 2-\mathrm{W} 1) /(\mathrm{V} 2-\mathrm{V} 1)$

\section{Optimization of culture media}

For the production of biofertilizer in large volume (10 I) by batch fermentation process, the culture was grown in the semi-synthetic media, where different cheap carbon sources, including starchy waste from boiled rice, potato mash, arrowroot etc were used. Saccharolytic activity of this strain was previously reported ${ }^{17}$. To the most cost effective medium $30 \mathrm{~g}$ of potato mash was added in $1 \mathrm{I}$ media as carbon source. Other ingredients were $\left(\mathrm{NH}_{4}\right)_{2} \mathrm{SO}_{4}-0.5 \mathrm{~g}$, yeast extract $1 \mathrm{~g}, \mathrm{CaCl}_{2}-0.5 \mathrm{~g}, \mathrm{MgSO}_{4}, 7 \mathrm{H}_{2} \mathrm{O}-0.2, \mathrm{~K}_{2} \mathrm{HPO}_{4}-0.8$ $\mathrm{g}, \mathrm{KH}_{2} \mathrm{PO}_{4}-0.2 \mathrm{~g}$. Potato mash was filtered with two layer cheese cloth filter and the filtrate was used as carbon source for the media. $2 \%$ inoculum was added and the medium was incubated at $30^{\circ} \mathrm{C}$ for 24 hours in a shaker-incubator (160 rpm). Initial biomass concentration $\left(\mathrm{X}_{0}\right)$ and final biomass concentration $(X)(\mathrm{mg} / \mathrm{ml})$ was determined for each media to calculate bioprocess productivity $(\operatorname{Pr})$ using the equation: $\operatorname{Pr}=\left(X-X_{0}\right) / t$, where $t$ was the fermentation time in hours.

\section{Storage of biofertilizer}

$50 \mathrm{~g}$ of biofertilizer was packaged in surface sterilized sealed plastic sachets and stored at $4^{\circ} \mathrm{C}$. Viable count of the biofertilizer was measured in every 15 days interval by standard plate count method.

\section{Determination of viability of biofertilizer}

The number of viable cells per $g$ of biofertilizer sample was periodically determined. A plate count assay in Pikovskaya agar medium was performed in every 15 days interval for that purpose. The counts were statistically verified by determining standard error of triplicate set of plates. 
Study of plant growth promotion by applying biofertilizer in pot condition

Effect of the biofertilizer was studied in 30 pots using Abelmoschus esculentus as test plant. Each pot contained about 5 kgs of loamy soil. Seeds of $A$. esculentus were sowed in surface soil of the pots. Biofertilizer was applied throughout the surface soil of the pots after 24 hours of sowing of seeds. Biofertilizer was prepared by growing the culture of A5-BRSC in nutrient broth for 24 hours at $30 \div C$ and the culture was mixed with charcoal (the carrier) at $1: 1$ ratio $(\mathrm{w} / \mathrm{v})$. The cell concentration of the culture applied to each pot was $2 \times 10^{6} / \mathrm{ml}$. No biofertilizer was applied to the control pots. All the test and control pots were kept in the sunny area and watered daily for 60 days. Morphological parameters were measured in regular intervals. Percentage of seed germination, root length and shoot length, number of leaves, area of leaves, flowering time, fresh weight and dry weight of the matured plants were noted both in control as well as in test plants. Number of germinated seeds was counted in both inoculated and un-inoculated pots after 7 days of applying biofertilizer. Vigor index (VI) was determined by measuring root length and shoot length of vindi seedlings and calculated by using the formula: $\mathrm{VI}=$ (mean root length + mean shoot length) $x \%$ of seed germination ${ }^{18}$. Leaf area was calculated by using the formula: $k x$ leaf length $x$ leaf width, where $k=0.75^{18}$. Fresh weight of plants was taken after 60 days of growth. For dry weight determination, plant parts were separated and dried in hot air oven at $75^{\circ} \mathrm{C}$ for 48 hours.

\section{Estimation of microbial activity in pot}

Total activity of aerobic microorganisms in both test and control pots were determined by carbon di-oxide evolution method ${ }^{19}$ and soil dehydrogenase assay ${ }^{20}$. In every 15 days interval 60 $\mathrm{g}$ of soil from each of the pots were withdrawn and divided into three parts. One part of the soil was taken for viable phosphate solubilizing microflora count in Pikovskaya agar plate. Rest of two parts of the soil was left for carbon di-oxide evolution assay and soil dehydrogenase assay.

Carbon di-oxide evolution from the soil is one of the best methods for measuring the activity of soil microorganisms. $50 \mathrm{~g}$ of moistened soil from each pot was collected in 1 I conical flask and a test tube with $15 \mathrm{ml}$ of $0.5 \mathrm{~N} \mathrm{NaOH}$ was kept inside the flask. The $\mathrm{NaOH}$ solution was previously titrated with primary standard $0.5 \mathrm{~N}$ oxalic acid solutions. The flask was incubated for 24 hours at $30^{\circ} \mathrm{C}$ by sealing it with parafilm. An empty conical flask (without soil) was treated in the same manner as 'negative control'. Next day the residual $\mathrm{NaOH}$ was titrated with standard $0.5 \mathrm{~N} \mathrm{HCl}$ in both negative control and soiled pots. The amount of carbon evolved was calculated by using the formula: (M.W. of carbon / M.W. of $\mathrm{CO}_{2}$ ) x volume of $\mathrm{HCl}$ consumed.

For soil dehydrogenase assay $6 \mathrm{~g}$ of air-dried soil was thoroughly mixed with $0.6 \mathrm{~g}$ of $\mathrm{CaCO}_{3}$ and the mixture was taken in sterile culture tube. $2.5 \mathrm{ml}$ of sterile water and $1 \mathrm{ml}$ of $3 \%$ aqueous Triphenyl Tetrazolium Chloride (TTC), the substrate, was added to the tube. One tube without soil was treated in the same manner and acted as control. All the tubes were incubated for 24 hours at $30^{\circ} \mathrm{C}$. After 24 hours $10 \mathrm{ml}$ of $100 \%$ methanol was added to each tube and the content was filtered through Wattman filter paper no. 5 and the filtrate was collected. The absorbance of the filtrate was noted in spectrophotometer at 485 $\mathrm{nm}$. The amount of product formed was estimated from the standard curve of the product Tri Phenyl Formazan (TPF). Activity of $1 \mathrm{ml}$ of the enzyme was expressed as $\mu$ moles of product formed $/ \mathrm{min}$ under the specified assay condition.

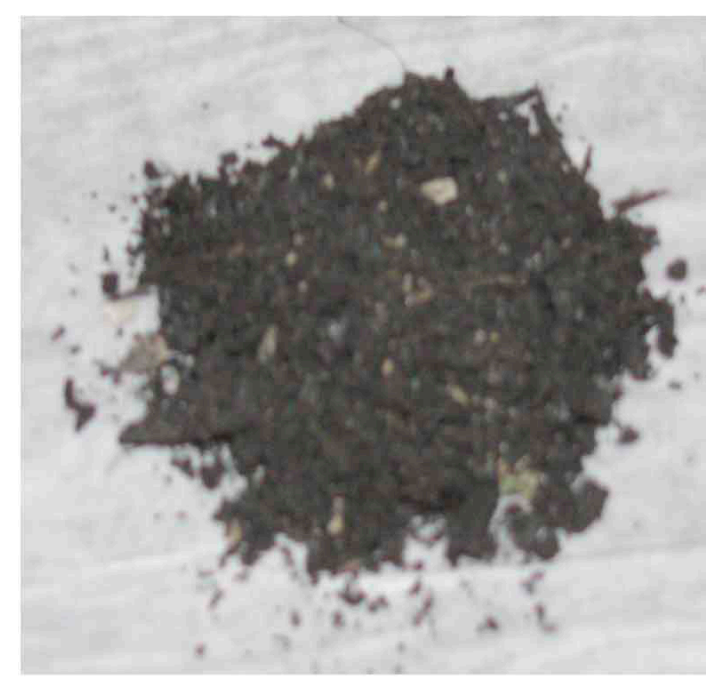

Fig. 1. Charcoal as carrier particle for biofertilizer application 


\section{RESULTS}

Due to good water holding capacity, neutral $\mathrm{pH}$, easy availability and long term viability of culture charcoal was found to be potent carrier for large scale production of biofertilizer (Fig. 1). The characteristics of the carrier are recorded in Table 1. Since the organism Bacillus thuringiensis A5-BRSC had great amylolytic activity, therefore easily available cheap starchy materials were used as carbon sources to make the medium cost effective. Among different carbon sources used for biofertilizer production, mashed potato showed highest biomass concentration and cell number in comparison to other carbon sources (Table 2).

Application of biofertilizer in pots using Abelmoschus esculentus as test plant

Application of Bacillus thuringiensis A5-BRSC culture as biofertilizer resulted in significant enhancement in seed germination as well as Vigor index in Abelmoschus esculentus. Seed germination was observed in both types of

Table 1. Physicochemical properties of the carrier used in biofertilizer production

\begin{tabular}{lc}
\hline Characteristics & Charcoal \\
\hline Colour & Black \\
Texture & Semi-fine \\
Odour & None \\
$\mathrm{pH}$ & Neutral \\
Moisture content (\%) & $21 \pm 4$ \\
Water retaining & 189 \\
capacity (\%) & \\
Bulk density (g/ml) & 1.42 \\
Carbon (\%) & $86.9 \pm 1.7$ \\
Shelf life of bacterial & 4 months \\
cells as biofertilizer & \\
\hline
\end{tabular}

pots after 72 hours of sowing. About $31.1 \%$ more seeds (out of 120 seeds in both inoculated and uninoculated pots) were germinated in biofertilizer inoculated pots within 7 days in comparison to control pots (Fig. 2). Initial root length (after 2 days of seed germination) in inoculated pots were 15 times higher than un-inoculated pots, but no significant difference was observed in initial shoot length of both test and control pots. Vigor index was calculated as 432 and 170 for inoculated and un-inoculated pots respectively. Root lengths of inoculated pots after 7 days of sowing of seeds were almost 1.3 times longer than control pots, but no significant increase of shoot length was observed in inoculated pots than control pots. Significant difference (at 0.05 levels determined by one-way ANOVA) in shoot length as well as in leaf area was observed 20 day onwards of seed germination (Fig. 3). Almost 1.5 times longer shoot length and 1.13 times thicker average shoot diameter, 1.2 times longer root length and 1.6 times larger leaf area was noticed in matured 30 days old plants (Fig. 4). Experimental

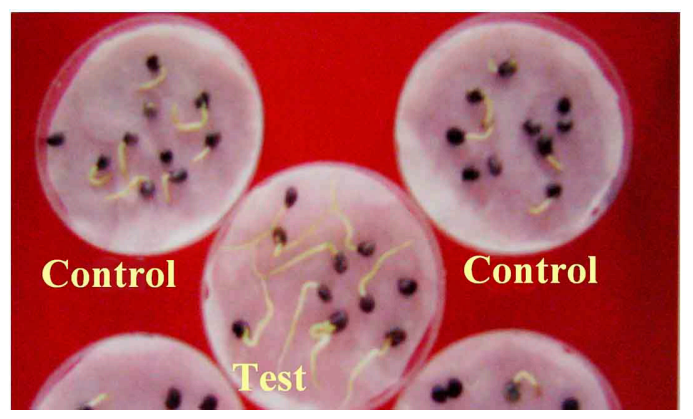

Fig. 2. Germination of Bacillus thuringiensis A5BRSC treated Abelmoschus esculentus seeds (test) in comparison to un-treated seeds (control)

Table 2. Bioprocess efficiency parameters of different media used in batch fermentation of biofertilizer production

Carbon source
used

\section{Starch waste of} boiled rice Potato mash Arrowroot Glucose (nutrient broth)

\begin{tabular}{ccc} 
& Parameters measured \\
\hline Final Cell density & Biomass concentration & bioprocess productivity \\
$(\mathrm{CFU} / \mathrm{ml})$ & $(\mathrm{mg} / \mathrm{ml})$ & $(\mathrm{mg} / \mathrm{ml} / \mathrm{h})$
\end{tabular}

$\begin{array}{lll}9.2 \pm 0.8 \times 10^{10} & 3.8 \pm 0.36 & 0.112 \pm 0.03 \\ 12 \pm 0.32 \times 10^{10} & 5.1 \pm 0.22 & 0.159 \pm 0.01 \\ 6.8 \pm 0.5 \times 10^{10} & 3.6 \pm 0.52 & 0.119 \pm 0.03 \\ 2.4 \pm 0.34 \times 10^{10} & 2.1 \pm 0.18 & 0.089 \pm 0.02\end{array}$


plants showed greater number of lateral roots than control plants. Application of biofertilizer increased significant amount of total fresh weight and dry weight of plants (Table 3).

Estimation of microbial activities in biofertilizer inoculated and un-inoculated pots

Both soil dehydrogenase assay and carbon di-oxide evolution assay showed that microbial activities were much higher in biofertilizer inoculated pots than control pots. The result of dehydrogenase assay implied that after the addition of biofertilizer in pots the microbial activity had a sharp rise on first 30 days and then gradually the activity become lowered, where as in control pots microbial activities remained more or less same for total period of 60 days. Similarly, high metabolic activity of aerobic soil microbes in biofertilizer inoculated pots were indicated by higher amount of carbon di-oxide evolution in first 30 days, where as almost similar $\mathrm{CO}_{2}$ evolution rate was observed in control pots during total study period of 60 days (Fig. 5).

\section{DISCUSSION}

The strain Bacillus thuringiensis A5BRSC showed better shelf life at $4^{\circ} \mathrm{C}$ when it is immobilized with charcoal as carrier. Moreover, due to more water containing capacity, neutral $\mathrm{pH}$ and easy availability made charcoal most suitable carrier for biofertilizer in this study.

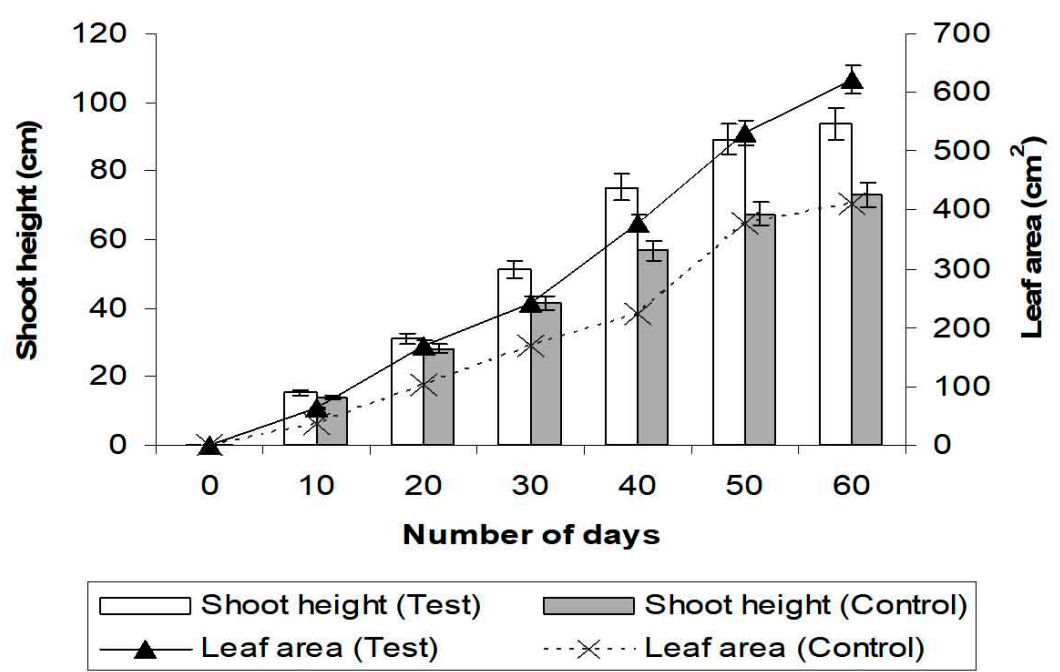

Fig. 3. Comparative analysis of shoot length and leaf area of Abelmoschus esculentus plant in both biofertilizer inoculated and un-inoculated pots

Table 3. Comparative morphological analysis of Abelmoschus esculentus plant in both biofertilizer inoculated and un-inoculated pots

\begin{tabular}{lll}
\hline Parameters measured & $\begin{array}{c}\text { Bacillus thuringiensis A5- } \\
\text { BRSC as biofertilizer in pots }\end{array}$
\end{tabular}

\begin{tabular}{lcc}
\hline Total no of plant studied & 30 & 30 \\
Average no. of fruits/ plant & 16 & 09 \\
Average Fruit weight $(\mathrm{g})$ & $19.03 \pm 0.42$ & $10.22 \pm 0.31$ \\
Fruit length \& diameter & $(12.36 \pm 0.08) \times$ & $(11.13 \pm 0.45) \mathrm{x}$ \\
(cm $\mathrm{cm}$ ) & $(6.08 \pm 0.17)$ & $(5.63 \pm 0.12)$ \\
Average no. of seeds/ fruit & $51 \pm 0.32$ & $45 \pm 0.08$ \\
Average seed weight (g) & $4.81 \pm 0.51$ & $2.74 \pm 0.24$ \\
Fresh weight of plant (g) & $54.97 \pm 1.7$ & $33.98 \pm 1.2$ \\
Total Dry weight of plant (g) & $13.0 \pm 1.2$ & $9.47 \pm 0.8$
\end{tabular}




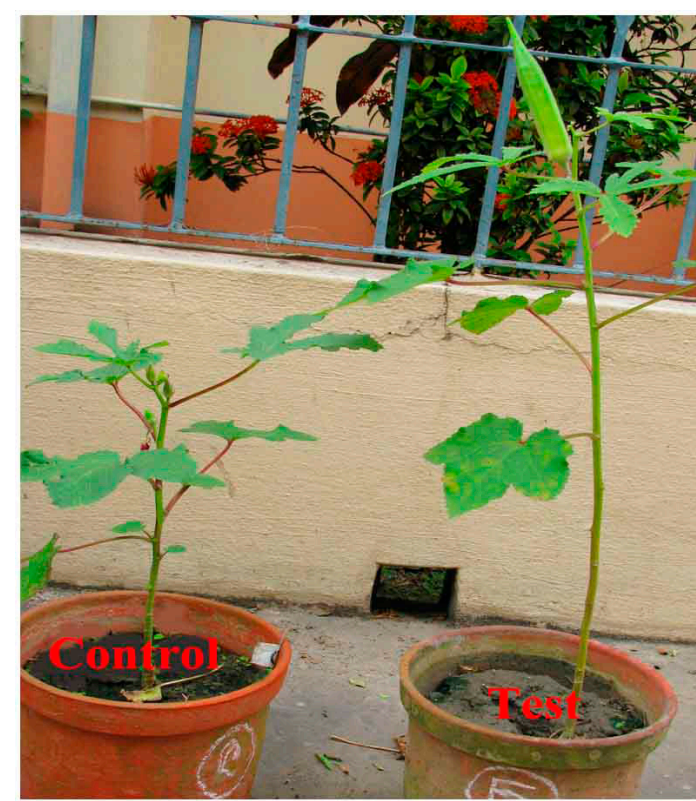

Fig. 4. Shoot height difference of 30 days old biofertilizer treated Abelmoschus esculentus test plant (right) against biofertilizer untreated control plant (left)
Therefore, from the commercial point of view charcoal-based biofertilizer seems to be economic for agricultural application. The faster growth rate of this isolate in low cost starchy substrates (due to its high amylolytic activity) makes large scale production of biofertilizer cost effective. Inoculation of Bacillus thuringiensis A5-BRSC in pots as carrier based biofertilizer increased the root length, shoot height and diameter, leaf area, fruit weight, fresh weight and dry weight of plants. Same pattern of result was also described by Mia et al. (2010) ${ }^{14}$. Their study with tissue cultured banana plant in pot condition revealed that introduction PGPR in pot not only increased initial root hair formation, but also increased plant height, leaf area, total leaf chlorophyll content and total dry matter accumulation. Similar pattern of growth promoting effects of PGPR in different nonleguminous plants were also reported by several other researchers ${ }^{21-24}$.

Microbial activities in charcoal based biofertilizer under pot condition measured by soil

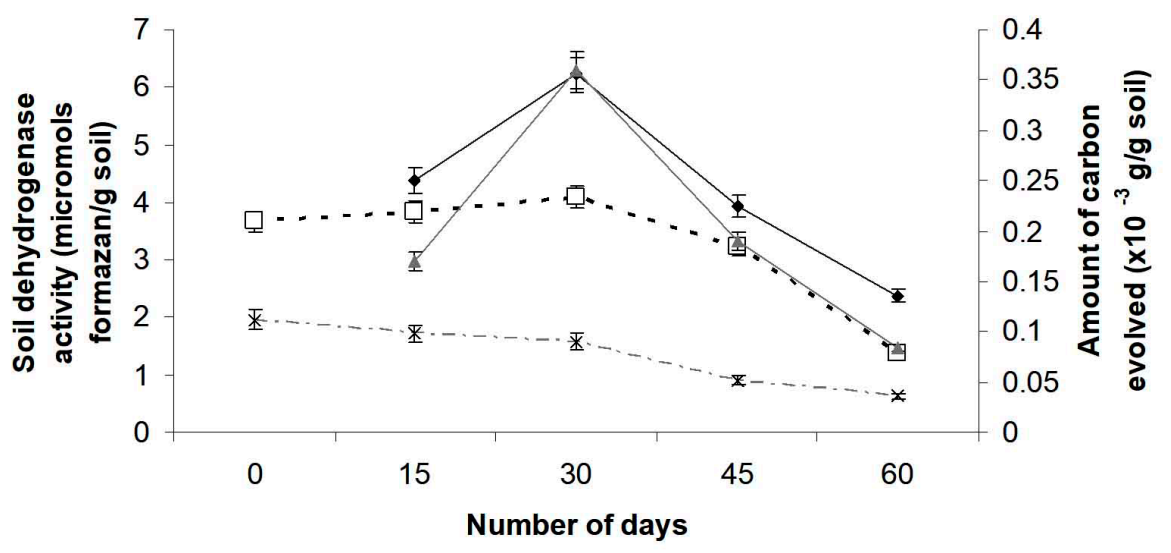

\footnotetext{
—-Dehydrogenase activity (Test) - - - - Dehydrogenase activity (Control)

_Amount of Carbon evolved (Test) _ - - **- Amount of Carbon evolved (control)
}

Fig. 5. Measurement of microbial activities in biofertilizer inoculated pots of Abelmoschus esculentus, compared to control pots by soil dehydrogenase assay and $\mathrm{CO}_{2}$ evolution method

dehydrogenase assay and $\mathrm{CO}_{2}$ evolution method, which reveals maximum active microflora of biofertilizer remains in first 30 days and after 45 days the activity of biofertilizer falls to a slower rate. The microbial activity pattern directly corelates growth promoting activities of plants. Similar pattern of result was reported by Jeon et al. $(2003)^{25}$. Their microcosm study revealed that most of the active microflora exist between 40-60 days.

From the present study it is evident that mass cultivation of this Bacillus thuringiensis biofertilizer is quite promising from the economic point of view, since low cost starchy substrates can 
be used due to the extra-cellular amylolytic activity of the microorganism. Moreover, the strain is quite stable in pot condition for long time and proved to be a potent strain for plant growth stimulation. Such multi-beneficial strains are needed for ecofriendly sustainable agriculture in modern days.

\section{ACKNOWLEDGEMENT}

The contribution of Dr. Swati Roy Gangopadhyay, Associate Professor, Department of Microbiology of Barrackpore Rastraguru Surendranath College, Kolkata - 700120 and Prof. Subrata Pal, retired Professor, Departement of Life Science and Biotechnology, Jadavpur University, Kolkata, West Bengal, India is highly acknowledged by the author.

\section{FUNDING}

None.

\section{DATA AVAILABILITY}

All datasets generated or analyzed during this study are included in the manuscript and/or the Supplementary Files.

\section{ETHICS STATEMENT}

This article does not contain any studies with human participants or with any animals.

\section{REFERENCES}

1. Sundara B., Natarajan V., and Hari K. Influence of phosphorus solubilizing bacteria on the change in soil available phosphorus and sugarcane and sugar yields. Field Crop Res., 2002; 77: 43-49. https://doi. org/10.1016/S0378-4290(02)00048-5

2. Chang C.H., Yang S.S. Thermo-tolerant phosphatesolubilizing microbes for multi-functional biofertilizer preparation. Bioresource Technol., 2009; 100: 16481658. https://doi.org/10.1016/j.biortech.2008.09.009

3. Alam S., Seth R.K. Comparative study on effect of chemical and biofertilizer on growth, development and yield production of paddy crop (Oryza sativa). Int. J. Sci. Res., 2014; 3(9): $411-414$.

4. Damir O., Mladen P., Bazidar, S, Srdan, N. Cultivation of the bacterium Azotobacter chroococcum for preparation of biofertilizers. Afr. J. Biotechnol., 2011; 10(16): 3104-3111. https://doi.org/10.5897/ AJB10.1086

5. Sharma A.K. Bio-fertilizers for sustainable agriculture, Mechanism of P-solubilization. Sixth Ed., Agribios publishers, Jodhpur, India, 2007.

6. Kumar V., Chandra A., Singh G. Efficacy of fly-ash based bio-fertilizers vs perfected chemical fertilizers in wheat (Triticum aestivum). Int. J. Engin. Sci. Technol., 2010; 2(7): 31-35. https://doi.org/10.4314/ijest.v2i7.63737
7. Boraste A., Vamsi K.K., Jhadav A., Khairnar Y., Gupta N., Trivedi S., Patil P., Gupta G., Gupta M., Mujapara A.K., Joshi B. Biofertilizers: A novel tool for agriculture. Int. J. Microbiol. Res., 2009; 1(2): 23-31.

8. Alam, G. A study of biopesticides and biofertilizers in Haryana, India, 2000.; pp 3-24. International Institute for Environment and Development: Sustainable Agriculture and Rural Livelihoods Programme, Gatekeeper Series no. 93.

9. Socolow R.H. Nitrogen management and the future of food: lessons from the management of energy and carbon. Proc. Natl. Acad. Sci., 1999; 96: 6001-6008. https://doi.org/10.1073/pnas.96.11.6001

10. Vance C.P. Symbiotic Nitrogen Fixation and Phosphorus Acquisition: Plant Nutrition in a World of Declining Renewable Resources. Plant Physiol., 2001; 127(2): 390-397. https://doi.org/10.1104/pp.010331

11. Narula N., Kumar N.V., Singh B., Bhatia R., Lakshminarayana K. Impact of biofertilizers on grain yield in spring wheat under varying fertility conditions and wheat-cotton rotation. Arch. Agron. Soil Sci., 2005; 51(1): 79-89. https://doi. org/10.1080/03650340400029382

12. Wu S.C., Cao Z.H., Li Z.G., Cheung K.C., Wong M.H. Effects of biofertilizer containing N-fixer, $\mathrm{P}$ and $K$ solubilizers and AM fungi on maize growth: a greenhouse trial. Geoderma., 2005; 125: 155-166. https://doi.org/10.1016/j.geoderma.2004.07.003

13. Chen J.H. The combined use of chemical and organic fertilizers and/or biofertilizer for crop growth and soil fertility, 2006; pp 1-11. International Workshop on Sustained Management of the Soil-Rhizosphere System for Efficient Crop Production and Fertilizer Use, Thailand.

14. Mia M.A.B, Shamsuddin Z.H., Wahab Z., Marziah M. Effect of plant growth promoting rhizobacterial (PGPR) inoculation on growth and nitrogen incorporation of tissue-cultured Musa plantlets under nitrogen-free hydroponics condition. Aus. J. Crop Sci., 2010; 4(2): 85-90.

15. Bandopadhyay S., Pal S., Gangopadhyay S. R. Isolation and characterization of plant growth promoting Bacillus thuringiensis from agricultural soil of West Bengal. Res. J. Biotechnol., 2011; 6(2): 9-13.

16. Walkley A., Black I.A. An examination of Degtjareff method for determining soil organic matter and a proposed modification of the chromic acid titration method. Soil sci., 1934; 37: 29 - 37. https://doi. org/10.1097/00010694-193401000-00003

17. Bandopadhyay S., Pal S., Gangopadhyay S. R. Fermentative production of thermostable alpha amylase from phosphate solubilizing Bacillus thuringiensis using soild substrates: Purification and characterization of the enzyme. Res. J. Biotechnol., 2013; 8(10): $42-49$.

18. Gholami A., Shahsavani S. and Nezarat S. The Effect of Plant Growth Promoting Rhizobacteria (PGPR) on Germination, Seedling Growth and Yield of Maize. World Acad. Sci. Engg. Technol., 2009; 49: 19-24.

19. Anderson J.P.E. Soil respiration, In Methods of soil analysis, part 2, 1982; pp. 837-871. $2^{\text {nd }}$ Ed., A.L. Page, R. H. Miller, and D. R. Keeney (ed.), Madison, Wisc.: 
ASA and SSSA.

20. Lenhard G. The dehydrogenase activity in soil as a measure of the activity of soil Microorganisms. $Z$. Pflanzenernaehr. Dueng. Bodenkd., 1956; 73: 1-11.

21. Bashan Y. Inoculants of plant growth promoting rhizobacteria for use in agriculture. Biotechnol. Adv., 1998; 16: 729-770. https://doi.org/10.1016/S0734 9750(98)00003-2

22. Bashan Y., Holguin G. and de-Bashan L.E. Azospirillumplant relationships: physiological, molecular, agricultural, and environmental advances. Can J. Microbiol., 2004; 50: 521-577. https://doi. org/10.1139/w04-035
23. Mia M.A.B., Shamsuddin Z.H., Zakaria W., Marziah M. High-yielding and quality banana production through plant growth promoting rhizobacterial inoculation. Fruits, 2005; 60: 179-185. https://doi.org/10.1051/ fruits:2005024

24. Shaukat K., Affrasayab S., Hasnain S. Growth responses of Triticum aestivum to plant growth promoting rhizobacteria used as a biofertilizer. Res. J. Microbiol., 2006; 1(4): 330-338. https://doi.org/10.3923/ jm.2006.330.338

25. Jeon J.S., Lee S.S., Kim H.Y., Ahn T.S., Song H.G. Plant growth promotion in soil by some inoculated microorganisms. J. Microbiol., 2003; 41(4): 271-276. 